\title{
AUTOESTIMA, FELICIDAD E IMPERATIVO ELPIDOLÓGICO: RAZONES Y SINRAZONES DEL (ANTI)EUDEMONISMO KANTIANO
}

\section{ROBERTO R. ARAMAYO}

\begin{abstract}
INSTITUTO DE FILOSOFIA
CONSEJO SUPERIOR DE INVESTIGACIONES CIENTIFICAS

Aquel placer (o desagrado) que necesariamente debe ir por delante de la ley, tal como suele ocurrir, es patológico; sin embargo, ese placer cuya comparecencia se ve precedida por la ley es de índole moral. El primero tiene como fundamento un principio empírico (la materia del arbitrio), mientras que el segundo alberga un principio puro a priori (basado tan sólo en una determinación formal de la voluntad). Tal distinción revela el sofisma en que discurre todo eudemonismo, para quien el placer (contento) que un hombre íntegro tiene a la vista para interiorizar en su conciencia una proba conducta, esto es, el horizonte o la esperanza de una felicidad ulterior, representa el auténtico móvil para orientar cabalmente su comportamiento (conforme a la ley). Ahora bien, en tanto que dicha conducta sea honrada y sumisa para con la ley, yo debo presumir que la ley precede al placer, a fin de que luego quepa experimentar un gozo anímico al cobrar consciencia del buen comportamiento; el eudemonismo se mueve, pues, en un estéril círculo vicioso donde se toma por causa del comportamiento lo que sólo es una consecuencia o corolario suyo (I. Kant, Acerca del tono aristocrático que viene utilizándose últimamente en la filosofla; Ak. VIII, 395-396 Anm.).
\end{abstract}

\section{Introducción}

A principios del presente siglo, en sus Lecciones introductorias al psicoanálisis (que datan de 1919), Freud nos habla de las tres grandes humillaciones que la ciencia habría infligido al ser ḥumano en su autoestima. Primero, la cosmología vino a comunicarle que su bienamado planeta no era el centro del universo, cuando Copérnico demostró que no era el sol el que giraba en torno a la tierra, sino ésta la que daba vueltas alrededor de aquél, haciéndole ver que incluso este astro no constituía sino una parte insignificante dentro de un inabarcable universo. Luego, Darwin le informaría que tampoco era el rey de la creación, tal como le habịan hecho creer ciertas convicciones 
religiosas y, lejos de ser la criatura predilecta del Creador, sólo era el descendiente de una cadena evolutiva que lo emparentaba con los monos, convirtiéndolo así en un simio algo sofisticado. Por último, el propio Freud le diría que ni tan siquiera era dueño y señor en su propia casa, por cuanto que la mente no conoce casi nada de un insconsciente donde se agazapan las auténticas e ignotas motivaciones del comportamiento humano.

Siglo y medio antes los teletipos filosóficos traían desde la remota Königsberg mejores noticias para nuestro narcisismo. Con su teoría del conocimiento, Kant emprende una "revolución copernicana" —como él mismo advierte al inicio de su Crítica de la razón pura (KrV, B XVII) - haciendo girar a los objetos en torno al sujeto, en vez de lo contrario. E igualmente, su ética, en lugar de fundamentar la moral sobre una concepción teológica predeterminada, subvertirá esta prevalencia, convirtiendo a la religión en una mera excrecencia de las premisas morales. El formalismo ético busca emanciparse de la religión, al igual que de cualquier otra exigencia o imperativo ajenos a su doctrina, la cual enuncia que los hombres no pueden ser utilizados como meros medios instrumentales ni tan siquiera por Dios, tal como Kant subraya en su Crítica de la razón práctica (KpV, Ak. V, 31). La religión no es el fundamento de la moral, sino en todo caso al revés (Refl. 6759), declara un Kant para quien Dios no es el origen de la ley moral, salvo que se identifique a Dios con la razón ético-práctica y autolegisladora -según sentencia el opus postumum (Ak. XXI, 145). En definitiva, buenas noticias para nuestra propia estima. Un concepto, éste de autoestima, que será capital en la ética de Kant, aun cuando sólo se llegue hasta él dando un largo rodeo en torno a la felicidad. Por ello, antes de arribar a este punto arquimédico del formalismo ético, tendremos que familiarizarnos con la concepción kantiana de la felicidad.

El formalismo ético de Kant suele caricaturizarse como una moral absolutamente rigorista que no considera para nada cosas tales como felicidad o el bienestar del hombre. Su obsesión por acatar el deber sin más miramientos que los de profesarle un sagrado respeto le haría enteramente insensible hacia ese tipo de preocupaciones, que ni siquiera se habría dignado a considerar. Sin embargo, a Kant sí le preocupaba mucho el tema de la felicidad, constituyendo ésta una cuestión que polarizó toda su reflexión ética. Para empezar, Kant define la felicidad como "la satisfación de todas nuestras inclinaciones". Uno será tanto más feliz, señala en la Crítica de la razón pura, cuántas más inclinaciones logre satisfacer, procurando además colmarlas en lo que atañe al grado de su intensidad y a la persistencia de su duración ( $\mathrm{KrV}$, A 806, B 834). 


\section{Los rasgos de la felicidad}

La total satisfacción de las propias necesidades e inclinaciones es lo que constituye nuestra dicha, escribirá el autor de la Fundamentación (Grundl. Ak. IV, 405). En la Crítica de la razón práctica se lee lo siguiente: "la felicidad es el estado de un ser racional en el mundo, al cual, en el conjunto de su existencia le va todo según su deseo y voluntad" (KpV, Ak. V, 125). Cualquiera podría suscribir sin grandes reparos estas definiciones kantianas en torno al concepto de felicidad, entendida como la satisfacción de nuestras necesidades e inclinaciones o el que todo nos vaya con arreglo a nuestros deseos. Ahora bien, el problema para Kant es concretar todo esto, es decir, averiguar en qué consiste realmente la felicidad. ¿En qué cifra su felicidad alguien que padece de gota? ¿Acaso prefiere continuar alimentando su gula u optará más bien por preservar su salud mediante la imposición de una dieta? Pero el asunto es mucho más complejo que una simple apuesta por preferencias de primera o segunda clase.

La felicidad, nos dice Kant, es un veleidoso ideal de la imaginación y su carácter es tan inestable que, aun cuando la mismísima naturaleza quisiera doblegarse puntualmente a los caprichosos antojos de nuestro mudable arbitrio, nunca lograría concordar del todo con ese titubeante concepto que tan pronto ciframos en una cosa como en la contraria.

El concepto de felicidad —escribe Kant en el § 83 de la Crítica del Juicio- no es un concepto que el hombre abstraiga de sus instintos, sino que representa la mera idea de un estado; a esa idea quiere el hombre adecuar su situación bajo condiciones meramente empíricas (lo cual es imposible). Él mismo bosqueja esa idea por medio de su entendimiento, confundido con la imaginación y los sentidos, cambiándola tan a menudo que, aunque la naturaleza estuviera totalmente sometida a su voluntad, no podría pese a todo forjar alguna ley universal y firme capaz de concordar con ese concepto titubeante, así como con el fin que cada cual se propone tan arbitrariamente. ( $K U, \mathrm{Ak}$. V, 430; p. 346)

Para Kant, "es una desdicha que el concepto de la felicidad sea un concepto tan indeterminado y que, aunque todo hombre desee llegar a ella, sin embargo nunca pueda decir de modo cierto y acorde consigo mismo qué quiere y qué desea propiamente" (Grundl., Ak. IV, 418), tal como se afirma en la Fundamentación. Así pues, lo primero que cabe reprochar a la felicidad es esta indeterminación, el que nadie sepa muy bien en qué la cifra con exactitud a cada instante, dado su carácter absolutamente veleidoso y mutable. No cabe fijar un critero cierto e infalible para su consecución, al tratarse de un concepto tan voluble. La felicidad -insiste Kant- "no es un ideal de la razón, sino de la imaginación y, al descansar en fundamentos empíricos, resulta vano esperar que determinen una acción por la cual se 
alcanzase la totalidad de una serie infinita de consecuencias" (Grundl., Ak. IV, 419). Para llevar a cabo semejante cálculo nos haría falta una inteligencia omnicomprensiva, como la fingida por Laplace para presentar su teoría de las probabilidades:

Una inteligencia que conociera en un momento dado todas las fuerzas que actúan en la naturaleza y la situación de los seres de que se compone, que fuera suficientemente vasta para someter estos datos al análisis matemático, podría expresar en una sola fórmula los movimientos de los mayores astros y de los menores átomos. Nada sería incierto para ella y tanto el futuro como el pasado estarian presentes a su mirada.

Esta hipótesis parece cada vez menos ficticia, máxime ahora que la computadora "Deep Blue" se las ha ingeniado para ganar a Kasparov analizando los movimientos realizados por el campéon mundial de ajedrez en sus partidas. A decir verdad, de contar con esta inteligencia omnicomprensiva (o un computador mucho más capaz y algo menos neurótico que aquel "Hall 9000" del relato imaginado por Arthur C. Clarke), no habría ninguna dificultad para suscribir el eudemonismo, ya que siempre nos encontraríamos en condiciones de pronosticar con absoluta certidumbre las condiciones más favorables para conseguir nuestra felicidad. Sin embargo, para Kant resulta evidente que "nadie es capaz de prefijar mediante algún principio y con plena certeza lo que le hará verdaderamente feliz, ya que para tal determinación sería indispensable tener omnisciencia" (Grundl., Ak. IV, 418). Y tal como señala en $L a$ paz perpetua, Kant está convencido de que "la razón no tiene luz suficiente para poder abarcar de una sola ojeada toda la serie de causas antecedentes y determinantes, lo que permitiría predecir con total seguridad el éxito favorable o adverso con que se ven rematadas las acciones u omisiones de los hombres según el mecanicismo de la Naturaleza" (Ak. VIII, 370).

La senda que conduce hacia la felicidad supone un auténtico laberinto en donde abundan las encrucijadas y sólo es una cuestión de suerte que acertemos a escoger la ruta más idónea. "La voluntad que sigue la máxima de la felicidad titubea, entre sus móviles, sobre lo que debe decidir, pues pone las miras en el éxito y éste no puede ser más incierto" (Gemeinspruch, Ak. VIII, 287). A juicio de Kant, la felicidad no sólo es algo inconcreto e imposible de fijar, sino que para colmo su consecución está en manos de algo tan impredecible como el respaldo del azar. Ese camaleónico y veleidoso ideal de nuestra imaginación presenta otro grave inconveniente: no depende tanto de nosotros como del azar, esto es, de que produzca una feliz coincidencia entre nuestros propósitos y las leyes que rigen mecánicamente la naturaleza. Para ser feliz hay que tener suerte, o sea, verse 
favorecido casualmente por la fortuna. La idea que nos interesa resaltar aquí es esa firme convicción kantiana, confesada en Teoría y práctica, de que, mientras "la felicidad abarca todo (y también únicamente) cuanto la naturaleza puede procurarnos, la virtud, en cambio, contiene aquello que sólo el hombre puede darse o quitarse a sí mismo" (Ak. VIII, $283 \mathrm{n}$.). El antieudemonismo profesado por el formalismo ético de Kant no desdeña la felicidad, como ahora veremos; el contraeudemonismo kantiano persigue, ante todo, la emancipación respecto del azar, no depender para nada de la veleidosa fortuna. En este sentido, resulta curioso que Victoria Camps le reproche a Kant (en La imaginación ética) forjar una moral a la medida de los dioses y no de los hombres, cuando precisamente lo que intentó Kant fue calibrar las fuerzas del hombre, con el fin de no exigirle más de lo que pudiera hacer por sí solo, autónomamente. Por otra parte, resulta ocioso prescribir la persecución de la felicidad, puesto que "todos los hombres tienen ya de suyo la más poderosa y ardiente inclinación hacia ella, en tanto que suma de todas las inclinaciones" (Grundl. Ak. IV, 399). Esta tesis de la Fundamentación será recogida doce años después por La metafísica de las costumbres: "Para la naturaleza humana es inevitable desear y buscar la felicidad, es decir, la satisfacción con la propia situación, en la medida en que hay certeza de que perdurará; pero precisamente por ello no es un fin que sea a la vez un deber" (Met. d. Sitten, Ak. VI, 387).

En todo caso, fomentar la propia felicidad puede suponer un deber mediato, encaminado a propiciar el auténtico deber, aquello que no depende sino de uno mismo: "asegurar la propia felicidad sí constituye un deber indirecto, habida cuenta de que su carencia conlleva un apremio por parte de muchas preocupaciones y esas necesidades insatisfechas acarrean a su vez una gran tentación a infringir los deberes" (Grundl., Ak. IV, 399).

Las adversidades, el dolor y la pobreza suponen grandes tentaciones para transgredir el propio deber. Por tanto, parece que el bienestar, el vigor, la salud y la prosperidad en general, que contrarrestan tal influjo, pueden considerarse también como fines que son a la vez deberes. Pero en tal caso el fin no es la propia felicidad, sino que lo es la moralidad del sujeto y apartar los obstáculos hacia tal fin constituye tan sólo el medio permitido, puesto que nadie tiene derecho a exigirme que sacrifique aquellos de mis fines que no son inmorales. (Met. d. Sitten, Ak. VI, 388)

Cuidarse de la propia felicidad representa, por lo tanto, un deber indirecto, habida cuenta de que alguien sumido en la pobreza o apremiado por cualquier otra necesidad puede caer con suma facilidad en la tentación de infringir sus deberes, mientras que lo contrario, esto es, preservar nuestra salud o no hallarnos en la indigencia, facilita la tarea de cumplir con el 
deber y mantener íntegra nuestra moralidad. Kant explica en su Crítica de la razón práctica que la distinción entre felicidad y moralidad no significa una necesaria oposición entre ambos conceptos, ni tampoco que "se deba renunciar a las pretensiones de la felicidad, sino únicamente que, al tratarse del deber, no se las tenga en cuenta" ( $K p V, A k . V, 93)$. Y ello por un puñado de buenas razones.

\section{Inventario del antieudemonismo kantiano}

Algunas de tales razones ya las hemos visto. Hagamos un pequeño balance:

(1) En primer lugar, no somos capaces de llegar a determinar con exactitud aquello en que ciframos nuestra felicidad.

(2) Y, por añadidura, si por alguna casualidad llegáramos a saberlo en un momento dado, tampoco podríamos conseguirla por nosotros mismos, ya que precisamos del apadrinamiento de la suerte. Sin contar con el azar o la fortuna no nos es posible hacernos felices y lo que Kant está buscando es un principio autónomo, cuya puesta en práctica no dependa sino de uno mismo.

(3) Pero es que ni siquiera es necesario prescribir la persecución de una felicidad propia, por cuanto esto es algo que ya se hace sin más y que, por lo tanto, no necesita ser prescrito como deber. Como dice Kant en su Metafísica de las costumbres:

La propia felicidad es un fin que todos los hombres tienen (gracias al impulso de su naturaleza), pero este fin no puede considerarse como un deber sin contradecirse a sí mismo. Lo que cada uno quiere ya de por sí de un modo inevitable no está contenido en el concepto del deber; porque éste implica una coerción hacia un fin aceptado a regañadientes. Por tanto, es contradictorio decir que estamos obligados a promover nuestra felicidad con todas nuestras fuerzas (Met. d. Sitten, Ak. VI, 386). Un mandato según el cual cada uno debe tratar de hacerse feliz, sería insensato, pues no se manda nunca a nadie lo que él ya quiere por sí mismo indefectiblemente. ( $K p V, A k$. V, 37)

Ahora bien, todavía hay otras razones que descalifican a la felicidad como posible principio rector de nuestra conducta moral.

(4) Según Kant, adoptar la felicidad como principio de nuestro comportamiento sólo consigue dar lugar a conflictos. Pues entonces cada cual persigue su propio bienestar y, aun cuando éste pueda coincidir por casualidad con las intenciones de los otros, tal cosa no basta para configurar una ley. Esta "coincidencia" sobre los fines perseguidos puede originar una pseudoarmonía semejante a la que se da entre un matrimonio mal avenido, cuyos cónyuges no quisieran sino arruinarse 
mutuamente, o generar un acuerdo tan conflictivo como el ejemplificado por Francisco I y su rival Carlos V, pues los dos querían exactamente lo mismo: conquistar el ducado de Milán ( $c f r . K p V$, Ak. V, 28). Este falso acuerdo respecto al fin apetecido, lejos de propiciar consenso alguno, como pretende la legislación moral que Kant quiere forjar, no auspicia sino desavenencias y toda suerte de conflictos. Pensemos en dos amigos enamorados de la misma mujer o, viceversa, en dos mujeres inclinadas a seducir al mismo hombre. En un caso como ése resulta claro que la coincidencia sobre los fines conducentes a propiciar nuestra propia felicidad no causará sino desdichas, al menos para uno de los tres cortejantes en liza (salvo que se mantenga en secreto alguno de los vértices del mencionado triángulo, por no hablar de figuras geométricas algo más complejas).

(5) A fin de cuentas, la felicidad se muestra incapaz de proporcionarnos un principio cuya validez sea universal, esto es, que no esté sujeto a infinitas excepciones y dependa del concurso de la mera casualidad. Para ser feliz no hay principios absolutamente certeros; únicamente contamos con ciertos consejos proporcionados por la experiencia y que han demostrado su éxito en situaciones más o menos parecidas, tal es el caso del ahorro, la dieta o el comedimiento, por citar los ejemplos del propio Kant. Estos consejos empíricos están hipotecados al concurso favorable del azar y, aunque se muestren eficaces para la mayoría de los casos, lo cierto es que no tienen una validez infalible para todos ellos, al ser fruto de una mera generalización inductiva. La felicidad es, en una buena medida, un regalo de la suerte, un don concedido caprichosamente por la fortuna y no algo que dependa de nosotros mismos.

\section{El concepto de autosatisfacción}

Con todo, hay una felicidad que sí depende única y exclusivamente de nosotros: hallarse contento con uno mismo. Hacia el final de la Crítica de la razón práctica Kant se pregunta lo siguiente: “¿acaso no hay ninguna expresión que señale, no un goce con el designado por la palabra 'felicidad', pero sí una satisfacción con la propia existencia, un análogo de la felicidad que acompañe necesariamente a nuestra conciencia del obrar virtuoso? Claro que sí -responde Kant-, y esa expresión es la del estar contento consigo mismo" (KpV, Ak. V, 117). Esta felicidad negativa, que no consistiría sino en eludir los remordimientos de la conciencia cuando se ha obrado mal, no cuenta para nada con el concurso de la suerte y no depende sino de nosotros mismos. Pero, por supuesto, esta "recompensa o salario" de la virtud, no 
tiene que ser tomado como el motivo del obrar virtuoso, sino como un corolario necesario del mismo. Kant insistirá mucho en este punto, para no caer en lo que da en llamar el círculo vicioso del eudemonismo, es decir, en considerar que la perspectiva del sosiego sirve de fundamento al obrar virtuoso. Además de abordar este problema en la segunda Crítica (como acabamos de comprobar), Kant vuelve a tratarlo en 1796, en la tercera nota del opúsculo titulado Acerca del tono aristocrático que viene utilizándose últimamente en la filosofía, y de nuevo en 1797, en la segunda parte de su Metafísica de las costumbres. En la Doctrina de la virtud Kant razona del siguiente modo:

El hombre reflexivo, una vez que ha vencido las incitaciones del vicio y es consciente de haber cumplido con un deber a menudo penoso, encuentra dentro de su ánimo una tranquilidad interior, un contento al que muy bien cabe llamar felicidad y oficia como una especie de recompensa o salario de la virtud. Ahora bien, el eudemonista (aquel que todo lo cifra en la felicidad) identifica ese gozo con el móvil que lo hace obrar virtuosamente, determinándose a cumplir con su deber gracias a esa perspectiva de felicidad. Sin embargo, resulta claro que, como sólo puede esperar recibir esta recompensa de la virtud mediante la conciencia del deber cumplido, ésta debe ir por delante; es decir, que ha de verse obligado a cumplir con' su deber antes de pensar, e incluso sin pensar, en que dicha felicidad será la recompensa de la observancia del deber. Por lo tanto, el eudemonista se mueve con esta explicación causal dentro de un círculo. Pues sólo puede esperar ser feliz (o interiormente dichoso) si es consciente de su observación del deber, siendo así que, a su vez, sólo puede ser llevado a observar su deber si prevé que con ello llegará a ser feliz. Pero en estas sutilezas del argumento eudemonista se encierra también una contradicción. Porque, por una parte, debe cumplir con su deber sin preguntar primero qué efecto tendrá esto en su felicidad, por lo tanto, merced a un motivo moral; pero, por otra parte, sólo puede reconocer algo como deber si puede contar con la felicidad que tal cosa le reportará y atendiendo por lo tanto a un principio patológico, que es justamente el contrario del anterior. El placer que ha de preceder al cumplimiento de la ley para obrar de acuerdo con ella es patológico y el comportamiento sigue entonces el orden natural; pero aquel placer que debe verse precedido por la ley para poder ser experimentado está dentro del orden moral.- Cuando esta diferencia no se respeta, cuando se instaura como principio la eudomonía (el principio de la felicidad) en lugar de la eleuteronomía (el principio de la libertad de la legislación interior), entonces la consecuencia es la eutanasia (la muerte dulce) de toda moral. (Met. d. Sitten, Ak. VI, 377-378)

Se diría que Kant está intentando convencerse sobre todo a sí mismo de cuanto sostiene aquí. Es como si al final de su obra quisiera matizar lo que había pensado él mismo muchos años antes. 


\subsection{La "Década del silencio"}

En efecto, Kant dedicó muchos años a coquetear con los conceptos de autoestima o autosatisfacción, tal como lo testimonian las Reflexiones pertenecientes a la llamada "década del silencio", ese dilatado periodo comprendido entre la Dissertatio y la primera Crítica (que abarca desde 1770 a 1781) en el que Kant no entrega ningún texto a la imprenta, pero no deja de anotar sus pensamientos. En estos fragmentos Kant insiste una y otra vez en explorar las posibilidades de que la autoestima o hallarse contento con uno mismo puedan oficiar como criterio de la moralidad, toda vez que, cuando menos, logra difuminar la zozobra causada por las reglas del cálculo eudemonístico y conlleva en cambio un gran sosiego. Entre 1764 y 1770 escribió cosas como éstas:

El modo más eficaz de estimular a los hombres hacia lo moralmente bueno es mostrar que uno sólo puede estimarse a sí mismo en cuanto se conforme con la virtud e igualmente que, aunque no se le persiga de modo consciente, el mayor sosiego acompaña a la ejecución del bien. (Refl. 6619, Antología de Kant, fragmento 21)

La doctrina de la virtud -leemos en la Refl. 6621-, antes que limitar los placeres de la sensibilidad, muestra más bien los distintos modos entre los cuales cabe elegir aquellos que mejor se compadezcan con la regla de un asentimiento universal. Abandonar esta pauta en aras del máximo provecho según el caso provoca un gran desasosiego dentro de nuestro ánimo; nuestro entendimiento proyecta reglas univerales conforme a las cuales organizar nuestros afanes de felicidad, armonizándolos entre sí, a fin de que nuestros ciegos impulsos no nos tengan de aquí para allá en pos de una presunta dicha. (Refl. 6621, fragmento 23)

Si las buenas acciones no reportaran jamás ventaja alguna y la dicha / fuera únicamente un premio a la astucia o una especie de lotería en la ruleta del azar, cualquier hombre sensato seguiría la regla moral con base en el sentimiento. Si pudiera obtenerse de modo inmediato la felicidad por este medio, la belleza moral quedaría enteramente devorada por el egoísmo y nunca podría obtenerse la estima del mérito. Con todo, la virtud no conlleva un provecho seguro: sus motivaciones han de asociarse con el beneficio que logra. (Refl. 6629, fragmento 30 )

Hacia 1770, Kant sigue insistiendo en que "cabe distinguir entre el contento con uno mismo y el mostrarse satisfecho con la propia situación; lo primero se refiere a la buena conducta, lo segundo atañe al bienestar" (Refl. 6632 , fragmento 31 ). Luego, a mediados de dicha década, presenta la virtud como una epigénesis de la felicidad:

El principio de la moral es la autocracia de la libertad con respecto a toda felicidad o la epigénesis de la felicidad conforme a leyes de la libertad. La felicidad 
carece de valor propio alguno en tanto que representa un don de la naturaleza o de la fortuna. El buen uso de la libertad es más valioso que la azarosa felicidad y el virtuoso detenta el principio de la epígenesis de la felicidad. El ordenamiento de las acciones conforme a leyes consensuales constituye al mismo tiempo la forma de toda felicidad. (Refl. 6867 (1776-1778); fragmento 102)

Sólo unos años después aparece la expresión "hacerse digno de ser feliz" vinculada con el contento con uno mismo:

El concepto de moralidad descansa en la dignidad de ser feliz (el contento de su voluntad en general). Al estar satisfechos con nosotros mismos, podemos ser dichosos sin contar con muchos placeres de los sentidos o con el apaciguamiento de sus exigencias. El sentirse satisfecho consigo mismo yergue el ánimo y constituye un gran móvil de la razón, si no es que el mayor. (Refl. 6892 (1776-1778); fragmento 106)

Yen 1780, la distinción entre amor propio y autoestima como criterios morales antagónicos ha quedado consagrada dentro del planteamiento kantiano, tal como testimonia la Reflexión 7242:

Los principios de la moralidad responden a los dictados de la Naturaleza o a la voluntad autolegisladora. En el primer caso, nos encontramos con el principio de la felicidad. En el segundo, con el de la dignidad de ser feliz. El uno queda encarnado en el amor propio (benevolencia hacia uno mismo). El otro en la propia estima (esto es, la satisfacción consigo mismo). Aquél repara en el valor de las circunstancias que rodean a una persona tal y como se presenta ante sus ojos. Éste no atiende al estado (Zustand), sino al valor de la persona misma, a su existencia (Dasein). El primero coloca la más alta condición del bien supremo en algo que depende sobremanera del azar. El segundo lo sitúa en algo que siempre se halla bajo nuestro poder. (Refl. 7242 (1780 ss.); fragmento 128)

\subsection{Un opúsculo inédito}

Hay un texto que requiere una especial atención a la hora de abordar el tema que nos ocupa. Me refiero a la Reflexión 7202. Los especialistas no han logrado ponerse de acuerdo respecto a su fecha; mientras que los comentaristas ingleses hablan de 1775, autorizados kantólogos como Adickes o Menzer sólo se aventuran a situarlo en la década de los 70. Sin embargo, todos coinciden en atribuirle una enorme importancia para comprender mejor el trasfondo de la moral kantiana. Y lo cierto es que no tiene desperdicio. Veamos algunos pasajes de dicho fragmento. La independencia del azar y el principio formal de la colibertad son presentadas como requisitos básicos 
o, aún mejor, como condiciones de posibilidad relativas a toda felicidad en general:

La materia de la felicidad es sensible, mas su forma es intelectual: no es posible concebir dicha forma sino como libertad sometida a leyes a priori que la hagan coincidir consigo misma, sin duda no para realizar de hecho la felicidad, sino la posibilidad e idea de la misma. Pues la felicidad consiste en el bienestar, siempre que éste no dependa de circunstancias empíricas, externas y azarosas, sino que descanse sobre nuestra propia elección, no tratándose aquí sino de una libertad bien ordenada.

El autodominio es presentado como una condición formal y sine qua non de la felicidad. Sólo quien se halle satisfecho consigo mismo por haberse liberado del apremio de las inclinaciones puede ser susceptible de ser feliz:

Sólo es susceptible de ser feliz quien se resiste a utilizar su libre arbitrio conforme a los datos relativos a la felicidad que le proporciona la Naturaleza. Esta propiedad del libre arbitrio es la conditio sine qua non de la felicidad. La felicidad no consiste propiamente en la mayor suma de placeres, sino en el gozo proveniente de la conciencia de hallarse uno satisfecho con su autodominio; cuando menos ésta es esencialmente la condición formal de la felicidad, aunque también sean necesarias (como en la experiencia) otras condiciones materiales.

A renglón seguido, Kant argumenta que dichas condiciones materiales escapan a nuestro control, al depender de la fortuna, invitándonos a reparar en aquello que sí somos capaces de producir autonómamente y que da en llamar autosatisfacción:

En el plano de los sentidos no cabe hallar una satisfacción completa, al no dejarse determinar con certeza y universalidad lo que resulta adecuado a sus necesidades; tales necesidades aumentan constantemente el nivel de sus exigencias, que permanecen eternamente insatisfechas, sin poder precisarse lo que les bastaría. La posesión de este placer resulta todavía menos cierta a causa de los vaivienes de la fortuna y de la contingencia propia de las circunstancias propicias. Sin embargo, el talante instruido por la razón para servirse apropiada y unánimemente de todos los materiales tendentes al bienestar se muestra certero a priori. Ahora bien, aunque sea cierto que la virtud cuenta con el privilegio de conseguir el mayor bienestar a partir de cuanto le brinda la Naturaleza, no estriba en este oficiar como medio su máximo valor, el cual queda cifrado en llevar aparejada una autosatisfacción que nosotros mismos podemos promover independientemente de las condiciones empíricas.

Como vemıs, este opúsculo inédito está consagrado por entero al examen de la noción de autosatisfacción o contento con uno mismo. Tras reconocer 
como necesaria una cota infraestructural mínima, sin la cual no es posible felicidad alguna, ya que - como la propia experiencia- la felicidad requiere ciertas condiciones materiales, Kant señala como requisito igualmente inexcusable o, es más, como conditio sine qua non de cualquier clase de felicidad, que uno se vea satisfecho consigo mismo, algo que define como una especie de apperceptio iucunda primitiva, esto es, como el apercibimiento de un sosiego, un estado de paz interior, cuyo logro no depende para nada del azar. Un paréntesis no desarrollado sugiere que Kant pudo pensar por un momento en la existencia de cierto paralelismo entre semejante apercepción primaria del sosiego interno y el papel desempeñado en su epistemología por la célebre apercepción trascendental.

Sin esta condición formal, prosigue Kant su razonamiento, el ser humano experimenta un autodesprecio que le arrebata lo más esencial, a saber, la estima que uno debe profesarse a sí mismo para sentirse una persona y no una mera cosa:

El hombre encuentra en su conciencia la causa de hallarse satisfecho consigo mismo. Posee la predisposición para todo tipo de felicidad y de hacerse feliz aún careciendo de las comodidades de la vida. En este nivel no existe nada real, en el sentido de que no se da ningún placer como material de la felicidad, pero, no obstante, constituye la condición formal de la unidad, que es esencial a cada cual y sin la que el desprecio de uno mismo nos arrebata lo más esencial del valor de la vida, es decir, la estima de la persona.

En este opúsculo inédito, en donde a mi juicio se representa un ensayo general del formalismo ético, el papel de protagonista estelar es asignado a ese principio apriórico de autosatisfacción que supone una condición formal para toda felicidad. Pero tampoco debe obviarse que dicho principio es generado a su vez por otro. Al final del texto Kant se pregunta por el fundamento de una prohibición tal como "no se debe mentir bajo ningún aspecto". Su respuesta es que dentro de nuestra conciencia moral nos encontramos con "un principio de reprobación y una inconsciente aversión interior, la cual ciertamente puede verse superada de vez en cuando por estimulos adversos, mas nunca erradicada". Este sentimiento de reprobación interna es el que, al fin y a la postre, generaría la propia estima en que Kant cifra el valor de toda persona y que puede ser definida negativamente como el sosiego de hallarse satisfecho consigo mismo por no autodespreciarse. Aunque parezca una enorme simplificación, el caso es que, a mi modo de ver, en el trasfondo de los planteamientos del formalismo ético kantiano se oculta este pulso que sostiene la estima contra el desprecio, destinado a conjurar cualquier posible remordimiento de una escrupulosa conciencia moral. Si bien es cierto que Kant optará por presentar las cosas de otro 
modo y camuflar ese mecanismo bajo la fórmula del "hacerse digno de ser feliz" o evitar la dignidad.

\subsection{El catecismo del Nachlass}

Ahora conviene dar un pequeño salto en el tiempo para leer una reflexión fechada en 1793 (es decir, cuando Kant ya ha publicado, no sólo la Fundamentación, sino también la segunda y tercera Críticas). En este fragmento, el catecismo de su Nachlass, Kant expone sucintamente sus tesis morales mediantes las preguntas y respuestas cruzadas entre un maestro y su discípulo; aquí se recogen las categorías de autosatisfacción y autodesprecio, aun cuando ya se hable del hacerse digno (o indigno) de la felicidad.

\section{Catecismo [fragmento 133]}

1) M: ¿Cuál es el mayor deseo que engloba a todos los demás?

D: Alcanzar cuanto pretendo y lograr cuanto deseo; en una palabra, ver satisfechas todas mis inclinaciones.

2) M: ¿Desearías entonces que, cuando quisieras mentir a alguien, éste siempre fuera tan ciego como para creerte y que esa falsedad nunca se materializara o que, cuando envidies la suerte de alguien, pudieras someterlo a tu antojo o apropiarte de sus pertenencias?

D: Por supuesto que no (resulta espantoso pensar así).

3) M: ¿No habíamos quedado en que te contentaba ver satisfechos tus deseos?

D: No del todo.

4) M: Veamos. Estarías satisfecho con lo que has logrado, puesto que lo deseabas, pero no con lo que has hecho para lograrlo, esto es, no contigo mismo. Pues a la hora de rendirte cuentas ante ti mismo, habrías de reconocerte como un embustero infame $\mathrm{y} /$ despreciable o como un abyecto estafador.

5) M: ¿Cómo se denomina el estado en el que se ven satisfechos (acaso sin su intervención) todos los deseos de un hombre?

D: No lo sé.

M: Felicidad; puesto que todo proviene de la dicha.

6) M: Por lo tanto, podrías ser feliz en sumo grado, estando sin embargo altamente insatisfecho. ¿Cúal es la razón de ello? El ser consciente de que no eres digno de esa felicidad.

7) M: ¿Puede alguien que te hace feliz, hacerte también digno de la felicidad o has de ser únicamente tú quien consiga tal cosa mediante sus actos?

D: He de serlo yo mismo.

8) M: ¿Cuál debería ser entonces el primero entre todos tus deseos, el de ser feliz o el de hacerte digno de la felicidad? 
D: Este último, es decir, obrar de forma que, cuando menos, no me haga indigno de ella.

M: En esa tarea consiste la auténtica libertad.

9) M: Existe, pues, una ley en ti y en tu razón que ciñe todos tus deseos al requisito de actuar así, y que se ha dado en llamar deber. Esta palabra significa que debes hacer cuanto sentencia esa ley sin plantearse utilidad alguna, sacrificando incluso tu mayor provecho, por muy onerosa e ingrata que resulte la acción; una ley semejante asevera: "no debes mentir". ¿Puedes ahora seguir cuestionándote qué prejuicios te acarrearía el mentir o las pingües ganancias que reporta en ocasiones la mendacidad? No, si en lugar de ponerte a deliberar sobre la opción de mentir, prestas atención a lo que se alcanza con la mentira: la indignidad. Y es que, en cuanto se deja oír la voz del deber, se acallan los cantos de sirena de la felicidad.

10) M: ¿Si estuviera en tu mano distribuir toda la felicidad, satisfarías de inmediato cualquier deseo?

D: Sí.

11) M: Eso demuestra que tienes buen corazón, iVeamos si con ello demostrarías tener también una buena cabeza! ¿Concederías al indolente cuanto desea sin que se hubiera esforzado por ello, al embustero una gran elocuencia para embaucar a los otros, al avariento cuanto le es posible arrebatar a los demás, al manirroto un tesoro inagotable, al despiadado la capacidad de hacer daño, etc.?

D: Claro que no.

12) $M$ : ¿Y por qué no, si lo que tú pretendes es satisfacer los deseos de todo hombre? Voy a decirte lo que habrías de pretender: aquel a quien quieres demostrar toda esa benevolencia debería mostrarse digno de aceptarla, esgrimiendo una buena voluntad para hacer uso de todo ese bien.

13) M: Sin duda, esta buena voluntad se hallará incluida en aquello que desea. Teniendo en tu mano la distribución de toda la felicidad, ino deberías proporcionarle también esa buena voluntad, $a$ fin de que no sólo estuviera contento con su estado sino también consigo mismo? ¿No hemos dicho que debe ser primero un buen hombre para hacerse digno de ser feliz?

D: Sí.

14) M: Por lo tanto, debe sacar de sí esa buena voluntad; nadie más puede dársela, puesto que siempre has de presuponer una buena voluntad para ser digno de alcanzar el cumplimiento de su deseo. La buena voluntad es, pues, el primer bien, que no puede ser otorgado por ningún otro, puesto que tampoco se puede comenzar a desear tenerla, si no se la posee ya en una buena medida. (Refl. 7315 (1792-1794)) 
ahora dirigirse a las Lecciones de Ética para ver cuál era el razonamiento seguido por Kanta ahí.

4. Las "lecciones de ética" y la piedra filosofal del formalismo ético: el imperativo elpidológico

Al tratar del principio supremo de la moralidad en sus Lecciones de Ética, Kant distingue dos momentos claramente diferenciados en la deliberación ética: el del discernimiento y el de la ejecución. Al primero le corresponde arbitrar una pauta de conducta, mientras que la competencia del segundo consistiría en encontrar un móvil para ejecutar dicha pauta. Las tres formulaciones del imperativo categórico nos proporcionan una pauta de conducta ética, pues el carácter universalizable de nuestra máxima, en cuanto no se contradice a sí misma, puede servir como una ley autónoma que rija para todos y eludir por añadidura tratar a los demás tan sólo como meros medios instrumentales. Ahora bien, según Kant, aun cuando nuestro entendimiento puede juzgar con relativa facilidad lo que resulta más atinado desde un punto vista moral, hallar una motivación para poner en práctica ese dictamen resulta mucho más problemático y "dotar a ese juicio de una fuerza que sirve de móvil para inducir a la voluntad a que acometa dicha acción es algo comparable a encontrar la piedra filosofal" (L.E. p. 83) dentro del terreno de la ética. De ahí que su imperativo categórico deba cumplimentarse con otro, al que yo he dado en llamar "elpidológico".

Tal como sentencia en sus Lecciones de Ética, para Kant "la felicidad no es el fundamento ni el principio de la moralidad (no puede serlo por todas las razones que veíamos en un principio), pero sin embargo —añade — sí ha de ser un corolario necesario de dicha moralidad" (L.E. p. 119). En esta lacónica sentencia se cifra la gran aporía que dinamiza todo el planteamiento ético de Kant. En su opinión, "seguir la idea de la moralidad sin albergar al mismo tiempo la esperanza de ser feliz, es algo sencillamente imposible" (L.E. p. 123). Y, por eso, la convertirá en el objeto elpidológico por excelencia, dotando a esa esperanza de felicidad, en el ámbito de la praxis, una función similar a la desempeñada por el conocimiento en el plano teórico, según se afirma en la Crítica de la razón pura, donde Kant mantiene que "todo esperar se refiere siempre a la felicidad y supone, con respecto a lo práctico y la ley moral, exactamente lo mismo que representa el saber y la ley natural en relación con el conocimiento teórico de las cosas" ( $K r V$, A 805-806, B 833-834). Este pasaje del Canon de la primera Crítica constituye todo un lema para el formalismo ético. Dentro del ámbito práctico esa esperanza de felicidad tiene tanto peso como el saber para la epistemología y representa para la ley moral tanto como las leyes naturales en el conocimiento 
teórico. Pues, aunque Kant siempre intenta delimitar las preguntas relativas cómo debo comportarme y al qué me cabe aguardar, siempre termina cuestionándose ¿qué puedo esperar si hago cuanto debo? Al comienzo de La religión dentro de los límites de la mera razón Kant argumenta que los hombres deberían conformarse con responder a su segunda pregunta sin interesarse demasiado por la tercera, pero enseguida se traiciona reconociendo que "un albedrío que sabe cómo, mas no hacia dónde tiene que obrar, no puede bastarse" (Rel., Ak. VI, 4). Y, como es bien sabido, esta orientación vendrá dada por la controvertida brújula del bien supremo.

"Si he actuado de manera que me haya hecho digno de la felicidad, entonces también puedo esperar disfrutar de dicha felicidad; tal es el móvil de la moralidad" (L.E., p. 119). Así queda resuelto en Lecciones de Ética el problema del móvil que Kant compara con la piedra filosofal. Sin embargo, Kant no dejaba de matizar esta consideración a sus alumnos, explicándoles que, si bien "el hombre puede esperar ser feliz, esa esperanza no ha de motivarlo, sino tan sólo confortarlo. Aquel que vive moralmente puede esperar ser recompensado por ello, pero no debe dejarse motivar por esa esperanza" (L.E., pp. 92-93). Ésta es la pirueta psicológica que la ética kantiana exige a quien se proponga comportarse moralmente y con la cual pretende zafarse del círculo vicioso en que incurren los eudemonistas. Podría pensarse que tales titubeos o contradicciones quedarian solventadas cuando pasamos del Kant precrítico al autor de las Críticas, pero lo cierto es que no es así en modo alguno, puesto que la distinción hecha en las Lecciones entre los planos del discernimiento y de la ejecución quedará sancionada en esa división entre "Analítica" y "Dialéctica" que estructura la Crítica de la razón práctica. El supremo bien es definido allí, no sólo como el objeto de una voluntad pura, sino como el fundamento de su determinación (Ak. V, 109-110), añadiéndose que su imposibilidad conseguiría convertir a la ley moral en algo fantástico, imaginario y falso (Ak. V, 115).

¿Qué significado tiene la doctrina kantiana del bien supremo? ¿Por qué la plantea Kant? Desde luego, no para colar de rondón una fundamentación teológica de la moral, como le reprocharon Heine o Schopenhauer, sino para no caer en la desesperación y apostar por la esperanza, tal como ha de hacer ese hombre recto, ejemplificado en el $\S 87$ de la Crítica del juicio por un ateo como Spinoza; este hombre justo, decidido a ejercer la ley moral sin abrigar ninguna mira interesada ni provecho propio alguno, al verse rodeado por la envidia y el engaño, para no caer en desánimo, debe creer que su moralidad puede llegar a modificar el actual orden de cosas. Por supuesto, ha de obrar como si todo dependiera única y exclusivamente del propio esfuerzo, mas no le viene mal confiar en que sus bien intencionados afanes quedarán coronados con el éxito (Rel., Ak. VI, 101). 
El "móvil" (entre comillas) que Kant oculta cuidadosamente tras la ley moral tendría, por lo tanto, una triple dimensión. Por una parte, no podemos renunciar a esperar una felicidad que nos hemos ganado, esto es, de la que nos hemos hecho dignos al obrar moralmente. Pero además de invertir en esa felicidad que debería desprenderse del obrar virtuoso como un corolario absolutamente necesario, también cobramos un rédito inmediato, como es el de sentirse satisfecho con uno mismo. Ahora bien, por añadidura, esta estima de sí o autosatisfacción conlleva otra cosa todavía más cierta, pues ahuyenta la indignidad, es decir, el tormento del menosprecio a que podrían someternos los remordimientos de nuestra escrupulosa conciencia moral.

Claro está que todo este planteamiento pivota sobre un condicional, como se advierte al final de la segunda Crítica; todo ello queda hipotecado al supuesto de que "el hombre nada teme tanto como hallarse ante sus propios ojos, en el examen interior de sí mismo, despreciable y repugnante" ( $\mathrm{KpV}$, Ak. V, 161). Kant, por supuesto, suscribía esta hipótesis y quería creer que "la transgresión del deber actúa sobre nuestro ánimo tornando al hombre reprobable y punible ante sus propios ojos" (Gemeinspruch, Ak. VIII), tal como afirma en su Teoría y práctica, para solventar el famoso ejemplo del depósito.

\section{A modo de conclusiones}

El antieudemonismo kantiano entrañaría, pues, un sofisticado eudemonismo, el cual reniega del tortuoso y laberíntico cálculo eudemonista por nuestra radical incompetencia para controlar todas las variables que pueden propiciar la felicidad entendida como satisfacción de los deseos, pero a cambio consigue una dicha segura como la del hallarse contento con uno mismo. Esta estima propia o autosatisfacción se origina tal como el placer comparece mediante la supresión del dolor. Uno se halla satisfecho consigo mismo cuando logra esquivar su inconsciente aversión a transgredir el deber y caer en la indignidad. Al acallar los posibles remordimientos de la conciencia moral, se logra un sosiego cuya consecución está por entero bajo nuestro control, puesto que no depende para nada del azar y la fortuna, como en el caso de la satisfacción de nuestras necesidades o anhelos. Además, este gozo negativo, resultante de regatear el desasosiego propio del remordimiento, se recrea con la esperanza de obtener aquella felicidad cuyo cálculo resultaba tan complejo, en tanto que la virtud nos hace dignos de ser felices, un requisito sin el cual no podríamos disfrutar de felicidad alguna, según Kant. La felicidad no sirve como principio moral, pero tampoco puede ser desterrada de ética, y por eso Kant viene a definirla como un corolario de la virtud. El imperativo categórico sirve para discernir aquello que debemos hacer. Sin embargo, el imperativo elpidológico, al invitarnos a 
esperar la felicidad en el marco del bien supremo, nos proporciona la piedra filosofal de un móvil desinteresado para ejecutar el deber:

El móvil -leemos en Teoría y práctica-que estriba en la idea del bien supremo posible en el mundo, gracias a nuestra cooperación, no es el de buscar en ello la propia felicidad, sino que dicho móvil viene dado por esa idea como fin en sí misma, o sea, por su persecución como deber. Pues esa idea no contiene una perspectiva de una proporción entre dicha felicidad y la dignidad del sujeto. Pero una autodeterminación de la voluntad que se autolimite a tal condición, no es una determinación interesada. (Gemeinspruch, Ak. VIII, 280 Anm.; p. 12 n.)

En definitiva, lo que he querido hacer aquí es desandar el camino que conduce a Kant hasta su noción de respeto. $Y$ en ese itinerario nos encontramos con que la dignidad (o el valor de una persona) viene a descansar en el concepto de autoestima, todo lo cual está basado a su vez en ese contento con uno mismo que genera la supresión del desasosiego producido por los dictámenes desfavorables de una conciencia moral cuya misión es activar este desprecio interior en cuanto se atente contra el deber.

\section{BIBLIOGRAFIA}

$A k .=$ Kant's Gesammelte Schriften. Hrsg. von der Königlich Preussische, bzw. von der Deutsche Akademie der Wissenschaften, Berlín et alia, 1902 y ss. (29 vols.). Gemeinspruch $=$ Teoria y práctica (versión castellana de Roberto Rodríguez Aramayo y Manuel Francisco Pérez López), Tecnos, Madrid, 1986 y 1993².

Grundlegung = Fundamentación de la metafísica de las costumbres (edición bilingüe y traducción de José Mardomingo), Ariel, Barcelona, 1996.

$K p V=$ Crítica de la razón práctica (reimp. supervisada por Juan Miguel Palacios de

la traducción de Manuel García Morente), Sígueme, Salamanca, 1994.

$K r V=$ Crítica de la razón pura (traducción de Pedro Ribas), Alfaguara, Madrid, 1978.

L.E. = Lecciones de Ética (versión castellana, estudio introductorio y notas de Roberto Rodríguez Aramayo), Crítica, Barcelona, 1988.

Met. $d$. Sitten = La metafísica de las costumbres (versión castellana de Adela Cortina y Jesús Conill), Tecnos, Madrid, 1989 y $1994^{2}$.

Refl. (reflexiones o fragmentos del Nachlass) = Antologia de Kant (selección, traducción y prólogo de Roberto Rodríguez Aramayo), Península, Barcelona, 1991. 